\title{
Processos educativos desvelados no conviver: curso equidade
}

The educational process revealed through students interaction: equality course

Los procesos educativos develados en el convivir: curso equidad

\author{
Alessandra Guerra da Silva Oliveira ${ }^{1}$; ANa Carolina APARECida Marques Soarez ${ }^{2}$; \\ GILMAR ARAÚJO DE OLIVEIRA ${ }^{3}$; NATÁlia LOPES DOS SANTOS ${ }^{4}$; LUCIENE APARECIDA DA SILVA ${ }^{5}$ \\ UNIVERSIDAde FEDERAL de São Carlos, UFSCAR, São Carlos-SP, BraSIL \\ academia da Força Aérea, AFA, Pirassununga-SP, Brasil \\ UniVERSIDAde ESTADUAL DE CAMPINAS, UNICAMP, CAMPINAS-SP, BRASIL \\ Secretaria da EducaÇão do Estado de São Paulo, SEE-SP, Sumaré-SP, Brasil
}

\begin{abstract}
RESUMO
O presente artigo busca compreender os processos educativos desvelados no conviver do curso de ação afirmativa "Equidade no acesso à pós-graduação para populações sub-representadas", no ano de 2012. Para isto, foi adotada a investigação qualitativa, inspirada na fenomenologia. No estudo foram analisados relatos de 8 participantes do curso. A análise dos dados possibilitou a configuração de seis categorias: A) Aprender a pensar e escrever de forma crítica, com autonomia; B) Aprender sobre o conceito de humildade; C) Vínculo de amizade, solidariedade, companheirismo; D) Acolhimento, diálogo, amorosidade; E) Fortalecimento do pertencimento étnico-racial, da negritude; F) Compromisso com a temática da educação étnico-racial e luta contra o racismo e desigualdades. Tais compreensões podem possibilitar alternativas à ausência de representantes negros e indígenas nos Programas de Pós-Graduação no Brasil e ajudar na criação de novas políticas públicas de ações afirmativas.
\end{abstract}

Palavras-chave: Processos Educativos. Equidade. Ações Afirmativas. Conviver.

\begin{abstract}
The present article seeks to understand the educational processes unveiled by living during the affirmative action capacitation "Equity in the postgraduation access for underrepresented population", in the year 2012. With this purpose, was adopted a qualitative investigation, inspired in the phenomenology. In this study were analyzed reports from 8 course participants. The data analysis allowed to configure into six categories: A) Learn to think and write critically, with autonomy; B) Learn about the humility concept; C) Friendship, solidarity and companionship bond; D) welcoming, dialogue and loving; E) ethnic-racial belonging strengthening, of blackness; F) Commitment with ethnicracial education thematic and fight against racism and inequalities. Such understanding can enable alternatives to the absence of black and indigenous representatives in the postgraduation programs in Brazil and help to create new affirmative public policies.
\end{abstract}

Keywords: Educational Processes. Equity. Affirmative Actions. Living.

\section{RESUMEN}

El presente artículo busca comprender los procesos educativos develados en el convivir del curso de acción afirmativa "Equidad en el acceso a la educación de postgrado a las poblaciones subrepresentadas" en el año de 2012. Para esto, fue adoptada la investigación cualitativa, inspirada en la fenomenología. El estudio analizó 8 relatos de los participantes del curso. El análisis de los datos tornó posible la configuración de seis categorías: A) Aprender a pensar y escribir de manera crítica, con autonomía; B) Aprender sobre el concepto de humildad; C) Vínculo de amistad, solidaridad, hermandad; D) La cálida bienvenida, el diálogo y la amorosidad; E) Fortalecimiento de la pertenencia étnico-racial y lucha contra el racismo y las desigualdades. Tales entendimientos pueden posibilitar alternativas a la ausencia de representantes negros e indígenas en los programas de postgrado en Brasil y ayudar en la creación de nuevas políticas públicas de acciones afirmativas.

Palabras clave: Procesos Educativos. Equidad. Acción Afirmativa. Convivir.

\footnotetext{
${ }^{1}$ Doutoranda no Programa de Pós-Graduação em Educação (PPGE) da UFSCar. E-mail: ale-unesp@ig.com.br. ORCID: http://orcid.org/0000-0002-2304-4052.

2 Oficial Magistério Superior Língua Espanhola da AFA. E-mail: anacarolinasoarez@gmail.com. ORCID: http://orcid.org/0000-0001-8023-2968.

3 Doutorando no PPGE/UFSCar. E-mail: araujodeoliveiragilmar@gmail.com. ORCID: http://orcid.org/0000-00027617-6235.

Mestranda no Programa de Pós-Graduação da Faculdade de Educação da UNICAMP. E-mail: nateducinfo@gmail.com. ORCID: http://orcid.org/0000-0001-5894-1020.

${ }^{5}$ Professora da SEE-SP. E-mail: lulatinalu@ hotmail.com. ORCID: http://orcid.org/0000-0002-6990-9955.
} 


\section{Introdução}

Vivemos em uma sociedade que se denomina democrática, mas existem racismo, discriminações e desigualdades que marginalizam as pessoas negras e indígenas, e as colocam como inferiores nas relações que estabelecem.

O Brasil não é um país de maioria branca, pois 56,20\% das pessoas da população brasileira se declararam pretas ou pardas, de acordo com a Pesquisa Nacional por Amostra de Domicílios Contínua (IBGE, 2019). No entanto, esse fato não faz com que as pessoas negras tenham as mesmas oportunidades sociais, econômicas e políticas das pessoas brancas.

As pessoas negras, em nosso país, respondem pelos mais baixos índices de desenvolvimento humano: moram nos piores lugares, têm menos tempo de estudo, ocupam os piores empregos, recebem os menores salários. Os únicos índices que são maiores referem-se à mortalidade e à população carcerária. Considerando as questões de gênero, mulheres negras apresentam os piores índices, são as mais prejudicadas e marginalizadas socialmente (IBGE, 2019).

Sobre a educação, no Brasil as escolas não incluem em seus currículos e planejamentos pedagógicos, as contribuições dos negros no desenvolvimento da nossa nação. Também não é realizada a inclusão de discussões sobre a história e a situação social dos negros na pós-colonização e modernidade. Nos livros didáticos, a história dos negros é tratada apenas de forma pejorativa/negativa, o negro somente é citado quando se fala em abolição e escravidão. A cultura negra embora presente em nosso cotidiano, é invisibilizada, inferiorizada nas escolas (SILVA, 2018).

De acordo com Freire, (2006, p. 112) numa perspectiva crítica e democrática do currículo: "[...] qualquer discussão em torno da realidade social, política, econômica, cultural, discussão crítica, nada dogmática, é considerada não apenas desnecessária, mas impertinente". Podemos dizer, assim, que a omissão e invisibilidade da cultura e história dos negros nos currículos escolares, da Educação Infantil ao Ensino Superior, foram e são intencionais. Discriminação que não acabou com o fim da escravidão.

Pensando nestas questões, em 2003, depois de muitas lutas do Movimento Negro e de estudiosos que se preocuparam com as questões étnico-raciais, foi aprovada em nosso país a Lei 10.639 (BRASIL, 2003), que estabelece a obrigatoriedade do ensino sobre 'História e Cultura Africana e Afro-brasileira' na educação básica de todas as escolas brasileiras, públicas e privadas. Posteriormente, em 2008, foi promulgada a Lei 11.645 (BRASIL, 2008), que estabelece as mesmas orientações quanto à temática indígena.

Em 2004, as Diretrizes Curriculares Nacionais para a Educação das Relações Étnico-Raciais e para o Ensino de História e Cultura Afro-Brasileira e Africana foram homologadas (BRASIL, 2004), com o objetivo de oferecer referências e critérios para regulamentar e complementar a Lei 10.639/03.

O documento (BRASIL, 2004) determina que o ensino da 'História e Cultura Afro-Brasileira' deverá divulgar a participação dos africanos e de seus descendentes em episódios da história do Brasil, na construção econômica, social e cultural de nossa sociedade, destacando a atuação dos negros nas diferentes áreas do conhecimento. $\mathrm{O}$ ensino nas escolas brasileiras também deve promover alteração positiva na realidade vivenciada pela população negra, buscando possibilitar uma sociedade mais justa e igualitária, revertendo as perversas heranças racistas e preconceituosas deixadas pela colonização.

Tal documento destaca, ainda, a importância de implementação de políticas de ações afirmativas, isto é, de políticas de reparação para ressarcir os danos psicológicos, 
materiais, sociais, políticos e educacionais causados à população de afrodescendente durante o sistema escravista. De acordo com as Diretrizes (BRASIL, 2004):

Cabe ao Estado promover e incentivar políticas de reparações, no que cumpre ao disposto na Constituição Federal, Art. 205, que assinala o dever do Estado de garantir indistintamente, por meio da educação, iguais direitos para o pleno desenvolvimento de todos e de cada um, enquanto pessoa, cidadão ou profissional. Sem a intervenção do Estado, os postos à margem, entre eles os afro-brasileiros, dificilmente, e as estatísticas o mostram sem deixar dúvidas, romperão o sistema meritocrático que agrava desigualdades e gera injustiça, ao reger-se por critérios de exclusão, fundados em preconceitos e manutenção de privilégios para os sempre privilegiados. Políticas de reparações voltadas para a educação dos negros devem oferecer garantias a essa população de ingresso, permanência e sucesso na educação escolar, de valorização do patrimônio histórico-cultural afro-brasileiro, de aquisição das competências e dos conhecimentos tidos como indispensáveis para continuidade nos estudos, de condições para alcançar todos os requisitos tendo em vista a conclusão de cada um dos níveis de ensino, bem como para atuar como cidadãos responsáveis e participantes, além de desempenharem com qualificação uma profissão (p. 3).

Embora a Constituição Federal de 1988 (BRASIL, 1988) estabeleça que o acesso à educação constitui-se um direito social de todos(as) os(as) cidadãos(ãs) brasileiros(as), a manutenção de mecanismos sociais, que discriminam de modo sistemático pessoas racialmente identificadas como negras e indígenas, faz com que suas experiências educativas sejam atravessadas por intensas desigualdades na utilização dos equipamentos escolares.

Conforme aponta Rosemberg (2006), as instituições de educação, quase sempre, são percebidas pelas crianças e pelos jovens afro-brasileiros como um ambiente hostil que, ora se manifesta indiferente à discriminação racial elegendo um currículo, material didático e livros de literatura que os desqualificam, ou até mesmo, omitem a contribuição do negro na formação cultural do Brasil, ora silencia diante de práticas de exclusões e atribuição de apelidos pejorativos a alunos e alunas negras.

A autora, citando Pinto (1993, p. 27), descreve:

Ao que tudo indica, a escola, que poderia e deveria contribuir para modificar as mentalidades antidiscriminatórias ou pelo menos para inibir as ações discriminatórias, acaba contribuindo para a perpetuação das discriminações, seja por atuação direta de seus agentes, seja por sua omissão perante os conteúdos didáticos que veicula, ou pelo que ocorre no dia-a-dia da sala de aula. Além disso, nota-se, até há poucos anos, pequeno empenho de instâncias governamentais e privadas de aprimorarem a formação de professoras no tocante aos direitos humanos.

Assim sendo, crianças e adolescentes negros se veem forçados a recorrer, desde muito cedo, a estratégias de resistência para combater as práticas preconceituosas e discriminatórias que sofrem.

Prosseguindo a leitura do trabalho de Rosemberg (2006), observa-se que as desigualdades educacionais não se limitam ao campo simbólico. No plano material, examina-se a presença significativa da população negra em instituições da rede pública de ensino, nas escolas classificadas como de má qualidade, onde os professores possuem formação inferior e circuitos intraescolares menos valorizados.

Mediante a esta situação, verifica-se que os alunos negros egressos das escolas públicas se encontram, involuntariamente, despreparados para participar dos processos 
seletivos que envolvem a disputa por uma vaga nas instituições de ensino superior, sobretudo, nas universidades públicas gratuitas, reconhecidas como de melhor qualidade.

Neste sentido, a formulação de políticas de ações afirmativas tem sido reivindicada pelo Movimento Negro como uma forma de assegurar condições básicas para que todos os estudantes descendentes de africanos negros consigam, dentro dos espaços educativos, desenvolver os requisitos, as competências e os conhecimentos considerados indispensáveis para atuarem como cidadãos responsáveis, participantes e qualificados para desempenhar uma profissão no mercado de trabalho (BRASIL, 2004).

De acordo com Campos (2018), é no final da década de 1960 e início da década de 1970 que as reivindicações por políticas de reparação passaram a ser pauta permanente nos debates realizados pelo movimento negro brasileiro. No entanto, foi a partir de 2003, durante o governo do então presidente Luiz Inácio Lula da Silva, que as ações afirmativas começaram a se consolidar.

Ao que tange os espaços educacionais, identifica-se a Universidade Estadual do Rio de Janeiro (UERJ), como a primeira universidade estadual a aderir ao Programa de Cotas nos processos seletivos para ingresso nos cursos de graduação. Conforme aponta Guarnieri e Silva (2017, p. 184):

\footnotetext{
Desde então, a quantidade de universidades que aderiram ao programa de cotas foi ascendendo rapidamente em um curto período. De 2003 a 2005, 14 universidades aderiram às cotas, sendo que em 2006 esse número chegou a 43, e em 2010 já somavam 83 instituições de ensino superior com cotas.
}

Em 29 de agosto de 2012, a presidente Dilma Rousseff sancionou a Lei ${ }^{\circ} 12.711$ que estabelece em seu primeiro artigo, a obrigatoriedade às instituições federais de educação superior vinculadas ao Ministério da Educação de reservarem nos concursos seletivos para ingresso nos cursos de graduação, o mínimo de 50\% das vagas para estudantes que tenham cursado integralmente o ensino médio em escolas públicas. Além disso, dentro destes $50 \%$, metade das vagas deverão ser destinadas a estudantes oriundos de família com renda per capita igual ou inferior a 1,5 salário-mínimo (BRASIL, 2012), favorecendo a inclusão social de estudantes provenientes das camadas sociais mais baixa nos contextos de educação universitária.

Importante ressaltar que tais deliberações ocorreram após a participação do Brasil na III Conferência Mundial das Nações Unidas contra o racismo, discriminação racial, xenofobia e intolerância correlata realizada pela ONU, na cidade de Durban, África do Sul, no ano de 2001, evento considerado mundialmente como marco fundamental no processo de elaboração e estabelecimento de ações políticas que visam o combate ao racismo e à discriminação racial (SILVÉRIO; TRINIDAD, 2012).

Embora a implementação de políticas públicas de ação afirmativa na educação superior seja vista por muitos brasileiros como uma política promissora para romper com paradigmas e diminuir as desigualdades educacionais existentes entre os diferentes grupos sociais e raciais que compõem a sociedade brasileira, tal fato é marcado pelos embates acalorados e dicotômicos entre os que defendem as cotas como iniciativa de valorização e inclusão étnico-racial e os que as condenam como prática discriminatória e inconstitucional. Para além disso, há ainda algumas questões para serem tratadas que envolvem todo o contexto no qual o cotista está sendo inserido. Assim como indica Guarnieri e Silva (2017, p. 189): 
ações que integrem e acomodem bem o aluno cotista. [...] chamam atenção para a questão da "permanência" dos alunos cotistas reiterando a importância de buscar por meio de ações concretas nas Universidades a fim de superar o teor assistencialista e unicamente econômico das mesmas. Exemplos dessas ações: aulas de reforço, bolsas de auxílio financeiro, bolsa alimentação, fornecimento de moradias, utilização do espaço universitário para promover continuamente a integração e a discussão sobre questões étnico-raciais e para a resolução de conflitos ou problemas de toda monta ligados ao tema.

No estudo de Rosemberg (2006, p. 4), observa-se que:

No atual cenário brasileiro, as experiências de AA voltadas para o acesso de egressos do ensino médio público, negros e indígenas ao ensino superior são de quatro tipos: a) aulas ou cursos preparatórios para acesso ao ensino superior e de reforço (melhoria do desempenho acadêmico); b) financiamento dos custos para acesso (inclusive no pagamento a taxas para o vestibular) e permanência no ensino superior; c) mudanças no sistema de ingresso nas instituições de ensino superior via metas, cotas, pontuação complementar etc.; d) criação de cursos específicos para estes segmentos raciais, tais como a licenciatura para professores indígenas da Universidade Federal de Roraima. Apenas duas experiências, a nosso conhecimento, vêm sendo desenvolvida com relação à pós-graduação. Uma delas é que vem sendo implantada pela Fundação Carlos Chagas desde 2002. Trata-se do Programa Internacional de Bolsas de Pós-Graduação da Fundação Ford que vem sendo coordenado, no Brasil, pela Fundação Carlos Chagas via atuação direta de três pesquisadoras do Departamento de Pesquisas Educacionais: Maria Malta Campos, Regina Pahim Pinto e eu mesma.

Com esses dizeres, compreendemos que as políticas de ações afirmativas se tornam necessárias para combater o racismo, a discriminação racial e garantir a equidade, o acesso e a permanência dos estudantes no sistema de ensino.

\section{UBUNTU}

Eu existo porque nós somos, pois fomos feitos para a condição de estarmos juntos. Somos feitos para a complementariedade. Somos criados para uma rede delicada de relacionamentos, de interdependência com os nossos companheiros seres humanos.

Pensamento Ubuntu, Desmond Tutu (TUTU, 2012, p.42).

Ubuntu é uma palavra existente nas línguas zulu e xhosa, faladas na África do Sul, que significa "eu sou porque nós somos". Eu me fortaleço não só para mim, mas também para minha comunidade, nas relações que estabelecemos com todas as pessoas.

Foi nesta perspectiva que este artigo foi se efetivando, sendo fruto de um curso de ação afirmativa que participamos no ano de 2012, ofertado pela Universidade Federal de São Carlos (UFSCar). O curso foi uma iniciativa da Pró-Reitoria de Pós-Graduação em parceria com a Pró-Reitoria de Extensão e intitulado "Equidade no acesso à pósgraduação para populações sub-representadas", com apoio das fundações Ford e Carlos Chagas que, no primeiro semestre de 2011, abriram chamada pública para universidades que já tinham experiência com ações afirmativas na graduação. Tendo sua proposta contemplada, foram destinados à universidade uma verba de $\mathrm{R} \$ 100$ mil aplicada nas duas ofertas do curso nos anos de 2012-2013, apoiando os/as candidatos matriculados com transporte terrestre, alimentação e material didático conforme recursos disponíveis (UFSCAR, 2012). 
As atividades eram desenvolvidas presencialmente, em encontros realizados aos sábados, e a distância, constituindo uma carga horária de 352 horas. Essas atividades foram organizadas em quatro blocos: redação acadêmica em Português; língua estrangeira instrumental - Inglês; metodologia de pesquisa e elaboração de projeto; e seminários temáticos (UFSCAR, 2012).

O curso tinha como objetivo promover a preparação acadêmica para fins de seleção em programas de pós-graduação no Brasil e no exterior, oferecendo um total de trinta vagas destinadas a candidatos/as negros/as, indígenas, candidatos/as deficientes visuais e deficientes físicos cadeirantes (UFSCAR, 2012). As experiências profissionais e de vida proporcionadas pelo curso, narradas nas aulas, nas conversas que tivemos e no convívio, foram significativas e marcaram grandemente nossa formação, por isso, sentimos grande necessidade de compartilhar tais experiências.

Munduruku (2019) discorre que para dizermos e revelarmos algo temos que ter vivido. Diante disto, buscamos neste artigo, descrever os processos educativos desvelados no conviver em grupo. Compreendemos que processos educativos, em acordo com Gonçalves Junior, Carmo e Corrêa (2015):

[...] ocorrem em uma relação mútua de aprendizagem e não só em uma situação em que um ensina ao outro, tendo como pressuposto fundamental para seu desenvolvimento o diálogo equitativo e a intencionalidade dirigida para a cooperação, superação, o ser mais, demandando autonomia, possibilidade de decisão e de transformação. Tais condições permitem aos envolvidos compreender em contexto, valores e códigos do grupo, da comunidade e da sociedade em que vivem, tendo a possibilidade de refletir criticamente sobre sua própria condição de pertencimento ao mundo com os outros, educando e educando-se (p. 176-177).

É com essa compreensão de processos educativos que objetivamos relatar a experiência de termos participado do curso "Equidade no acesso à pós-graduação para populações sub-representadas" no ano de 2012.

\section{TRAJETÓRIA METODOLÓGICA}

Com a intencionalidade de descrever e compreender os processos educativos desencadeados em um grupo de pessoas que participaram do Curso de Extensão "Equidade no acesso à pós-graduação para populações sub-representadas" no ano de 2012, foi adotada a perspectiva de investigação qualitativa. Para isso, nos orientamos pela Fenomenologia, entendendo-a como o estudo das essências e voltada à compreensão das experiências vividas pelos sujeitos face aos fenômenos, na procura do contato originário com outrem ao mundo em intersubjetividade (MERLEAU-PONTY, 1996).

Segundo Machado (1994):

A preocupação central desta trajetória de pesquisa se dá com o ato de compreender, mais do que explicar o objeto de estudo. A fenomenologia significando discurso esclarecedor a respeito daquilo que se mostra por si mesmo, enquanto uma práxis ou forma de ação, opera através do método que investiga a experiência, no sentido de compreendê-la e não de explicá-la. Compreender diz respeito a uma forma de cognição que diverge da explicação. Compreender é tomar o objeto a ser investigado na sua intenção total, é ver o modo peculiar específico do objeto existir. Explicá-lo é tomá-lo na sua relação causal (p. 35). 
Participaram do estudo, oito pessoas, sendo seis mulheres (Dandara, P1, Mayumi, Violeta, Anaya e Maira) e dois homens (Cadu e Anselmo).

Salientamos que os nomes dos/as participantes foram alterados, garantindo sigilo e privacidade; para isso, utilizamos nomes fictícios escolhidos por eles/as.

Em busca de compreender e coletar os dados, cada participante colaborou assinando o Termo de Consentimento Livre Esclarecido (TCLE) e redigindo um relato posteriormente à conclusão do curso-, de modo contextualizado, sistematizado e com objetividade, ponderando sobre sua participação no curso, descrevendo sua trajetória pessoal, experiências e aprendizados na convivência com colegas e professores/as. Cada um dos relatos, de cada participante, trazia em si os desafios vividos durante o curso, as descobertas, aprendizados individuais e coletivos, detalhando todo o caminho percorrido, do início das aulas à entrega do projeto de pesquisa, trabalho exigido para a conclusão do curso, assim como os anseios de ingressar em um programa de pósgraduação.

Para a análise, esses relatos foram submetidos a leituras minuciosas, buscando significar a experiência vivida dos/as colaboradores, buscando apreender "[...] da leitura de cada descrição as 'unidades de significado', enquanto aspectos que impressionam o pesquisador, dentro de seu campo perceptual, para chegar à evidência das experiências" (MACHADO, 1994, p. 41). Construídas as unidades de significado, essas foram agrupadas em categorias temáticas, objetivando movimento intencional em busca da essência do fenômeno pesquisado (BICUDO; ESPÓSITO, 1994; MARTINS; BICUDO, 1989).

Esse movimento, segundo Machado (1994):

[...] caracteriza-se pela busca da essência ou da estrutura do fenômeno. Ao ver que o fenômeno se ilumina diante de si, o pesquisador reconhece-se ligado ao sujeito pesquisado por uma relação dialética entre o seu horizonte conceitual e a experiência do sujeito, onde através da intersubjetividade, estabelece objetivamente os seus resultados (p. 41).

E desta maneira, após leituras e releituras dos relatos, com a realização de análise qualitativa inspirada na Fenomenologia, da classificação dos elementos presentes emergiram seis categorias: A) Aprender a pensar e escrever de forma crítica, com autonomia; B) Aprender sobre o conceito de humildade; C) Vínculo de amizade, solidariedade, companheirismo; D) Acolhimento, diálogo, amorosidade; E) Fortalecimento do pertencimento étnico-racial, da negritude; F) Compromisso com a temática da educação étnico-racial e luta contra o racismo e desigualdades.

\section{CONSTRUÇÃO DOS RESULTADOS}

\section{A) APRENDER A PENSAR E ESCREVER DE FORMA CRÍTICA, COM AUTONOMIA}

Nos relatos realizados pelos participantes do curso, percebemos essa passagem da consciência acrítica para a crítica e a explicitação de como esse processo foi doloroso e desanimador, para muitos. Alguns participantes descreveram a dificuldade em acompanhar o curso, devido às regras, conceitos e normas acadêmicas às quais não estavam habituados.

Além da dificuldade com o domínio da língua portuguesa em sua variante acadêmica, uma das participantes relatou dificuldades encontradas para aprender a língua inglesa, que para muitos alunos é de difícil acesso, pois apesar de ser ensinada 
nas escolas regulares brasileiras durante muitos anos, em muitos casos, os alunos não adquirem o mínimo necessário para leitura e interpretação de texto, por exemplo.

Segundo os relatos:

\begin{abstract}
A dificuldade de ler, entender, escrever, interpretar me deixou várias vezes desanimado, pois havia uma lacuna enorme, o despreparo (Anselmo). Foi difícil entrelaçar as linguagens à convencionalmente utilizadas nas pesquisas com uma "escrita engajada". A cada aula [...] "me reconheci "transgressor", "compósito", "participante” e "dialógico" e não estava só (Cadu).

Tivemos momentos intensos, difíceis. O nervoso tomava conta de mim, mas no decorrer das aulas estavam os salvadores da Pátria os professores que traziam sua bagagem de experiência e comprometimento com a turma (Anselmo).

Ao construir o meu projeto senti pressão, agonia e muitas vezes vontade de desistir do meu sonho, "cursar um mestrado", por não conseguir escrever. Com o grupo tive de aprender a pensar e escrever criticamente, com autonomia, e a refletir sobre a nossa realidade social e racial (Dandara).
\end{abstract}

Com Freire (1987) sabemos que a educação é um ato cultural que pode ser tanto bancária, legitimadora da opressão, usada para reforçar as desigualdades entre os homens $\mathrm{e}$ as mulheres, como também pode ser emancipadora-libertadora, transformando sujeitos e mundos em algo melhor, humanizados.

Freire (1987) nos ajuda a refletir sobre a concepção da educação bancária, dominadora, na qual o educador deposita os conhecimentos nos educandos, cabendo a estes apenas receber, memorizar e repetir sem entender o significado do que está sendo transmitido. Na concepção bancária os educandos não são chamados a conhecer e dialogar, apenas memorizam o que recebem. Freire (1987) nos propõe uma educação pela qual os indivíduos se tornam sujeitos do ato de se educar. Tornam-se conscientes de si mesmos, inseridos no mundo em que vivem.

Na concepção freiriana, a libertação é uma práxis que implica na ação e reflexão do indivíduo sobre o mundo em que ele vive para transformá-lo. É a passagem de uma consciência acrítica e ingênua para uma consciência crítica que visa à autonomia, ao diálogo e à humanização.

\title{
B) APRENDER SOBRE O CONCEITO DE HUMILDADE
}

Com Freire (2005) sabemos que a humildade demonstra uma das raras certezas de que podemos ter, a certeza de que ninguém é superior e melhor que ninguém.

"Somente quem escuta paciente e criticamente o outro, fala com ele, mesmo que, em certas condições, precisa falar a ele" (FREIRE, 2005, p. 113).

Ponderando esses dizeres, e considerando que as relações que estabelecíamos eram horizontais, nas quais ninguém sabia mais que ninguém, tivemos que ouvir as pessoas e aceitar opiniões diferentes das nossas para avançarmos nos conhecimentos, tínhamos que ao mesmo tempo nos expor e falar o que a gente pensava para colaborar na elaboração dos projetos dos outros participantes.

Uma das participantes relatou que na época de realização do curso na UFSCar ela era recém-formada no curso de Letras e com toda a sua ânsia de aplicar aquilo que aprendia, muitas vezes não conseguia escutar o outro, mas no decorrer do curso em 2012 teve que aprender a ouvir, o que transformou sua prática docente e a maneira de entender os processos educativos.

Segundo relatos: 
Este processo, apesar de muito bonito, também foi incômodo para mim, o que foi importante para o meu crescimento, pois muitas vezes ouvi da professora que eu não sabia escutar. E como disse o grande mestre Paulo Freire, e aprendi com ela na prática, o processo educativo exige uma escuta atenta do outro, de suas necessidades, antes de despejarmos as nossas verdades (P1).

Aprendi sobre o conceito de humildade, pois tive que ouvir as pessoas e a aceitar opiniões diferentes da minha para poder avançar nos conhecimentos; tive que ao mesmo tempo me expor, falar o que eu pensava para colaborar na elaboração dos projetos dos outros participantes (Dandara).

Os professores do "Equidade" e os colegas me abriram os olhos para dar visibilidade às experiências resistentes ao contexto presentes na sala de aula em articulações didáticas significativas (Cadu).

Levando em consideração os ensinamentos freirianos, aprendemos na prática que o processo educativo exige uma escuta atenta do outro, de suas necessidades, antes de despejarmos as nossas verdades. Assim, em nossa comunidade de trabalho não existia a negação do que as outras pessoas estavam fazendo, pois sabíamos dos esforços e processos que todos nós estávamos passando.

\section{C) VÍNCULO DE AMIZADE, SOLIDARIEDADE, COMPANHEIRISMO}

Os/as participantes do curso criaram um vínculo de amizade e companheirismo tão fortes, que permanecem até os dias atuais. A todo o momento, mesmo nos intervalos das aulas, trocávamos experiências, materiais (livros, artigos), líamos os projetos uns dos outros, para assim crescermos juntos, na construção dos projetos de pesquisa, na formação profissional e pessoal.

Compartilhamos tudo o que conseguimos, muitos colegas de curso desistiram, mas os que ficaram, souberam compartilhar aqueles momentos de encontro, eles nos fortaleciam, nos tornava mais humanos (Violeta).

Às vezes me perguntava o que causava tanta empatia com aquele grupo tão diverso? Hoje concluo que a empatia vem da identificação com o processo e trajetória de cada indivíduo desse grupo. Nos identificamos, sentimos que pertencemos ao mesmo universo. Todas e todos passamos por processos idênticos de rejeição, de desconstrução identitárias, de discriminação racial por termos nossos traços fenotípicos vinculados a negatividade entre tantas outras crueldades e, profundamente cravados com maldade na história do processo de dominação e exploração. Nos identificamos por termos a gana de lutar para que nenhum outro ser humano precise passar pelo que passamos (Maira).

A cooperação e a solidariedade também fizeram parte de todos os encontros. Todos que podiam, se ofereciam para ajudar. Alguns ofereciam suas casas para hospedar os/as amigos/as, compravam vale-refeição no Restaurante Universitário durante a semana, pegavam ou entregavam livros na biblioteca, levavam alguém de outra cidade até à rodoviária, levavam nas aulas um café, um lanchinho, um sorvete, pois sabiam que o/a amigo/a teria que pegar a estrada para voltar para casa.

\section{D) ACOLHIMENTO, DIÁLOGO, AMOROSIDADE}

O acolhimento também foi um sentimento desvelado nos processos educativos apreendidos. Relações respeitosas, em que o diálogo e a amorosidade permeavam entre amigos/as, professores/as, coordenador do curso (na época era o Pró-Reitor de PósGraduação), sem hierarquias, foi o que sentimos desde o primeiro encontro. 
O Pró-reitor da pós-graduação ficava entre nós, como entusiasta do trabalho que realizaríamos, e gostava de ouvir nossas histórias. Acho que nunca vou me esquecer dessa postura (Violeta).

Destaco aqui algumas experiências vivenciadas no período. Dentre elas a forma respeitosa e afetuosa com que a equipe do curso nos tratou; [...] a ida que fizemos à exposição dos quadros [...] de nossa colega de turma, no Centro Municipal de Cultura Afro-Brasileira "Odette dos Santos" em São Carlos-SP; nossa visita a Biblioteca Comunitária da UFSCar; as palestras de formação (Maira).

O diálogo, a amorosidade e a afetividade são descritas por Freire (1987) como sendo a própria superação da situação opressora; é o encontro dos homens e mulheres para o ser mais. Segundo Freire (1987, p. 46), “[...] ao fundar-se no amor, na humildade, na fé nos homens [e mulheres], o diálogo se faz numa relação horizontal, em que a confiança de um polo no outro é consequência óbvia".

Podemos dizer que nos sentimos acolhidos, respeitados e que essa postura adotada por todos os envolvidos no curso foi crucial para a nossa permanência.

\section{E) FORTALECIMENTO DO PERTENCIMENTO ÉTNICO-RACIAL, DA NEGRITUDE}

Participar deste grupo, formado por pessoas negras, também possibilitou para muitos dos participantes, o fortalecimento étnico-racial. Em todos os relatos realizados, foi citado esse processo educativo.

Muitos/as relataram que se viram negros/as, sentiram orgulho de suas origens, no convívio com as pessoas negras que já tinham sua identidade étnico-racial fortalecida.

Segundo os relatos:

Nas interações e vivências, comecei a me ver negra, comecei a refletir sobre meus valores e os referenciais provindos de minha origem, bem como a identificação das discriminações e preconceitos sofridos em minha infância e adolescência (Dandara).

O curso trouxe o fortalecimento da negritude, autoestima e orgulho de ser descendente africano, penso que cada um de nós refletir sobre nossa própria História, ressignificando o que aprendemos de nosso povo [...] Cada um de nós nos responsabilizamos em plantar as sementes de esperança, para a valorização da equidade para todos (Anselmo).

No curso Equidade pude pela primeira vez me ver como negra, sentir orgulho de minha origem, de minhas raízes. Eu me sentia muito à vontade com meus amigos irmãos, companheiros de luta, de vivências tão diferentes e ao mesmo tempo tão semelhantes, havia um sentimento de pertencimento muito grande entre nós (P1).

$\mathrm{O}$ curso da equidade me fez perceber o apagamento de minhas origens africanas. Não tive contato com minha avó paterna que era negra [...] Foi no curso que ouvi, Cadu, pela primeira vez a palavra "griô" e seu significado (Maira).

Me senti contemplada e ao mesmo tempo muito privilegiada por estar ao lado de pessoas que me orientavam e me ajudavam a fortalecer minha negritude. Foi uma experiência incrível (Anaya).

A gente se sentia nas histórias, nas fotos, nas dificuldades e nas famílias, que às vezes precisavam acompanhar um ou outro colega até o curso. Essa compreensão mútua me impulsionou pra vida, me transformou a partir daquilo que eu sempre fui e me fez continuar resistindo do meu próprio lugar (Violeta).

Com Souza (1983, p. 77) sabemos “[...] que ser negro não é uma condição dada, a priori. É um vir-a-ser. Ser negro é tornar-se negro". Nesta concepção, ser negro, vai 
além da cor da pele, textura do cabelo, das características físicas, mas uma opção política de reconhecimento e valorização das origens africanas.

Assim, o fortalecimento da negritude dos participantes só foi possível, como nos atenta Silva (2009), porque nós convivemos com os participantes do curso, que eram pessoas negras que já tinham o seu pertencimento étnico-racial fortalecido, e neste convívio pudemos dialogar e trocar experiências.

\section{F) COMPROMISSO COM A TEMÁTICA DA EDUCAÇÃO ÉTNICO-RACIAL E LUTA CONTRA O RACISMO E DESIGUALDADES}

Nos relatos, percebemos que muitos dos/as participantes desenvolveram seus projetos para terem acesso ao mestrado com o tema da educação das relações étnicoraciais, e muitos começaram a trabalhar com esta temática com seus alunos nas salas de aula, conforme relatos abaixo:

\footnotetext{
A equidade também contribuiu para que eu repensasse o modo como vinha vivendo na época. Não é exagero afirmar que participar do curso ressignificou toda minha vida! A partir dali me empenhei em voltar aos estudos (Maira).

Continuou os estudos com a temática étnico-racial- voltei à UFSCar para fazer um curso de "africanidades" na Educação (Violeta).

$\mathrm{O}$ curso da Equidade me proporcionou uma expansão de consciência que aplico na minha vida (Mayumi).

Em minha prática docente, agora com mais maturidade, tento aplicar um pouquinho de tudo que aprendi com os amigos e professores do curso. Foi e sempre será uma experiência marcante em minha vida (P1).

Compreendi durante o curso que a posição de educadora me obriga a assumir um posicionamento ético e político contrário a toda situação de discriminação e me habilita a promover uma educação antirracista nos espaços educacionais (Anaya).

O espanto da "Amolação Interrompida" frutificou hoje em muito mais que um professor mestre em Educação, minhas então conexões entusiásticas [...] no "campo da Educação" espaço este que hoje sou um guerreiro ainda mais resistente e crítico (Cadu).
}

Nossa participação no curso de extensão "Equidade no acesso à pós-graduação para populações sub-representadas" na UFSCar possibilitou, portanto, não apenas importantes ferramentas acadêmicas, mas promoveu, sobretudo, o fortalecimento de nosso compromisso político e social. Revelou a necessidade da luta de combate ao racismo e às discriminações, isto é, uma luta para que as vivências e práticas, como a que tivemos a oportunidade de vivenciar, não sejam um privilégio de apenas um grupo, mas um direito garantido para todos/as os/as educandos/as.

\section{CONSIDERAÇÕES FINAIS}

A gente somos

Segundo Munduruku (2019) a expressão "a gente somos", tem um sentido bem profundo. Poderia ser taxado como falta de concordância gramatical, mas trata-se de compreensão cósmica, é quando o sujeito se percebe parte e pertencente a um grupo, e assim, tornam-se irmãos, deixam o individualismo, e começam a pensar no bem de todos/as, na coletividade. 
Ensinamentos que vão ao encontro das ponderações de Freire (1987, p. 39) quando discorre que "[...] ninguém educa ninguém, como tampouco ninguém se educa a si mesmo; os homens [e as mulheres] se educam em comunhão, mediatizados pelo mundo". Pensando desta forma, consideramos que a formação de todo ser humano se desenvolve nas experiências que compartilhamos com outras pessoas e o meio social; fomos convivendo no curso equidade e fortalecendo o entendimento do termo "conviver", significamos como "viver experiências juntos", estabelecendo relações de confiança, diálogo e respeito, nas quais ninguém era mais sábio que ninguém.

Ao conviver com diferentes pessoas do curso, mais e menos experientes, fomos nos redescobrindo e nos fortalecendo como grupo. Aprendemos, ensinamos, trocamos experiências que marcaram nossa essência. Assim, se passaram oito anos e os laços de amizade, militância e compromisso com a educação das relações étnico-raciais se mantiveram, e a ânsia de disseminar nossa experiência e sentimentos expandiram-se.

Esse curso de ação afirmativa proporcionou, para muitos dos/as participantes, o acesso à pós-graduação, e mais importante que isso, proporcionou processos educativos que marcaram significativamente a todos/as. Aprendemos, como nos dizeres freirianos, "a ser-mais": mais humanos, mais humildes, mais críticos aos problemas sociais.

Ao relatarmos a experiência que vivenciamos, pudemos refletir sobre a importância do trabalho coletivo, realizado em comunhão, como sendo primordial para superarmos as dificuldades e alienações que nos foram impostas. Consideramos que as políticas públicas de ações afirmativas, como essa que participamos, são essenciais para reverter os efeitos da colonização, corrigir as desigualdades sociais entre pessoas negras e brancas, possibilitando, assim que as pessoas negras possam ter acesso à educação com maior equidade.

\section{REFERÊNCIAS}

BICUDO, M. A. V.; ESPOSITO, V. H. C. (org.). Pesquisa qualitativa em educação: um enfoque fenomenológico. Piracicaba: Editora UNIMEP, 1994.

BRASIL. Ministério da Educação. Lei $\mathbf{n}^{\mathbf{0}}$ 12.711, de 29 de agosto de 2012. Dispõe sobre o ingresso nas universidades federais e nas instituições federais de ensino técnico de nível médio. Brasília: MEC, 2012.

BRASIL. Ministério da Educação. Lei no 11.645, de 10 de março de 2008. Inclui no currículo oficial da rede de ensino a obrigatoriedade da temática "História e Cultura Afro-Brasileira e Indígena". Brasília: MEC, 2008.

BRASIL. Ministério da Educação. Diretrizes curriculares nacionais para a educação das relações étnico-raciais e para o ensino de história e cultura afro-brasileira e africana. Brasília: MEC, 2004. Disponível em: http://portal.mec.gov.br/dmdocuments/cnecp_003.pdf. Acesso em: 15 jul. 2020.

BRASIL. Ministério da Educação. Lei no 10.639, de 9 de janeiro de 2003. Inclui no currículo oficial da Rede de Ensino a obrigatoriedade da temática "História e Cultura Afro-Brasileira". Brasília: MEC, 2003.

BRASIL. Constituição da República Federativa do Brasil de 1988. Brasília: Casa Civil, 1988.

CAMPOS, L. L. Políticas públicas de ações afirmativas: um estudo da implementação da Lei 10.639/2003 e as suas implicações nas redes municipais de ensino de Porto Seguro - BA, Vitória da Conquista - BA e São Carlos - SP. 2018. Dissertação (Mestrado em Educação) - Faculdade de Educação, Universidade Estadual de Campinas, Campinas, 2018.

FREIRE, P. Pedagogia da esperança: um reencontro com a Pedagogia do oprimido. 13. ed. Rio de Janeiro: Paz e Terra, 2006. 
FREIRE, P. Pedagogia da autonomia: saberes necessários para à prática educativa. 31. ed. São Paulo: Paz e Terra, 2005

FREIRE, P. Pedagogia do oprimido. 17. ed. Rio de Janeiro: Paz e Terra, 1987.

GONÇALVES JUNIOR, L.; CARMO, C. S.; CORRÊA, D. A. Cicloviagem, lazer e educação ambiental: processos educativos vivenciados na Serra da Canastra. Licere, v. 18, n. 4, p. 173-208, 2015.

GUARNIERI, F. V.; SILVA, L. L. M. Cotas universitárias no Brasil: análise de uma década de produção científica. Revista Psicologia Escolar e Educacional, v. 21, n. 2, p. 183-193, maio/ago. 2017.

IBGE. PNAD Continua. Características gerais dos domicílios e dos moradores 2019. Disponível em: https://biblioteca.ibge.gov.br/visualizacao/livros/liv101707_informativo.pdf. Acesso em: 15 jun. 2020.

MACHADO, O. V. M. Pesquisa qualitativa: modalidade fenômeno situado. In: BICUDO, M. A. V.; ESPOSITO, V. H. C. (org.). Pesquisa qualitativa em educação: um enfoque fenomenológico. Piracicaba: UNIMEP, 1994. p. 35-46.

MARTINS, J.; BICUDO, M. A. V. A pesquisa qualitativa em psicologia: fundamentos e recursos básicos. São Paulo: Moraes/EDUC, 1989.

MERLEAU-PONTY, M. Fenomenologia da percepção. 2. ed. São Paulo: Martins Fontes, 1996.

MUNDURUKU, D. Das coisas que aprendi: ensaios sobre o bem-viver. 2. ed. Lorena: DM Projetos Especiais, 2019.

PINTO, R. P. Movimento negro e educação do negro: a ênfase na identidade. Cadernos de Pesquisa, n. 86, p. 25-38, ago. 1993.

ROSEMBERG, F. Ação afirmativa no ensino superior brasileiro: pontos para reflexão. 2006. Disponível em: https://www.adusp.org.br/files/GTs/etnia/acao2.pdf. Acesso em: 18 jul. 2020.

SILVA, P. B. G. Educação das relações étnico-raciais nas instituições escolares. Educação em Revista, v. 34, n. 69, p.123-150, 2018.

SILVA, P. B. G. A palavra é... africanidades. Presença Pedagógica, v. 15, n. 86, mar./abr. 2009.

SILVERIO, V. R.; TRINIDAD, C. T. Há algo novo a se dizer sobre as relações raciais no Brasil contemporâneo? Revista Educação e Sociedade, v. 33, n. 120, p. 891-914, jul./set. 2012.

SOUZA, N. S. Tornar-se negro: as vicissitudes da identidade do negro brasileiro em ascensão social. Rio de Janeiro: Edições Graal, 1983.

TUTU, D. Ubuntu: sobre a natureza da comunidade humana. In: TUTU, D. Deus não é cristão e outras provocações. Rio de Janeiro: Thomas Nelson Brasil, 2012. p. 41-44.

UFSCAR. Pró-Reitoria de Pós-Graduação lança projeto de equidade no acesso à pós-graduação. Diário da Reitoria, 15 fev. 2012. Disponível em: https://www.diariodareitoria.ufscar.br/?p=98. Acesso em: 15 jun. 2020.

Recebido em: 24 jul. 2020.

Aprovado em: 31 ago. 2020. 